\title{
Undiagnosed Chilaiditi syndrome presenting with pericarditis in a patient with congenital anomalies
}

\author{
Mir Inzamam Ali, ${ }^{1}$ Basset El Essawy, ${ }^{1,2,3}$ Sasmith Menakuru ${ }^{4}$
}

'RAK College Of Medical Sciences, Ras-al-Khaimah Medical and Health Sciences University, UAE

${ }^{2}$ Department of Internal Medicine, IBHO Hospital, RAK, UAE

${ }^{3}$ Renal Division, Transplantation Research Center, Brigham and Women's Hospital /Harvard Medical School, Boston, USA ${ }^{4}$ Department of Internal Medicine, Narayana Medical College and Hospital, Nellore, India

\section{Correspondence to} Dr Basset El Essawy, Abdel.essawy@rakmhsu.ac.ae

Accepted 6 June 2018

\section{DESCRIPTION}

A 19-year-old male patient presented to the emergency room with dyspnoea and severe retrosternal chest pain. The patient's medical history is significant for cerebral palsy with spastic tetraplegia. He layed in a semirecumbent position as pain was severe on lying down. The pain radiated to the back, neck and shoulder. Pain was associated with gastro-oesophageal reflux disease and dysuria. On examination, he was breathless, and lungs were clear to auscultation. On auscultating over the heart, pericardial rub was heard. Abdomen was tender on palpation and he did not defecate for 2 days. He had a history of recurrent pneumonia that needed frequent hospital admissions and currently receiving treatment as the last episode was 1 month ago.

ECG showed widespread concave ST elevation and PR depression with reverse changes in aVR of ST depression and PR elevation with sinus tachycardia suggesting early stage of pericarditis. Sputum culture was negative. Chest X-ray was done (figure 1) and revealed an area of previous pneumonia in the right lung and enlarged left border of heart, which was not definitive of pericarditis because of the rotational effect of his scoliosis, but raised the need for further investigation into the presumptive diagnosis of pericarditis. C reactive protein was elevated on laboratory investigation. Transthoracic echo was not significant besides that all other findings met the criteria for the diagnosis of pericarditis, that is, at least two from (1) characteristic chest pain, (2) pericardial rub, (3) ECG changes (widespread ST elevation and/or PR depression) and (4) new pericardial effusion. While examining the X-ray further, the most remarkable finding was the presence of large intestine

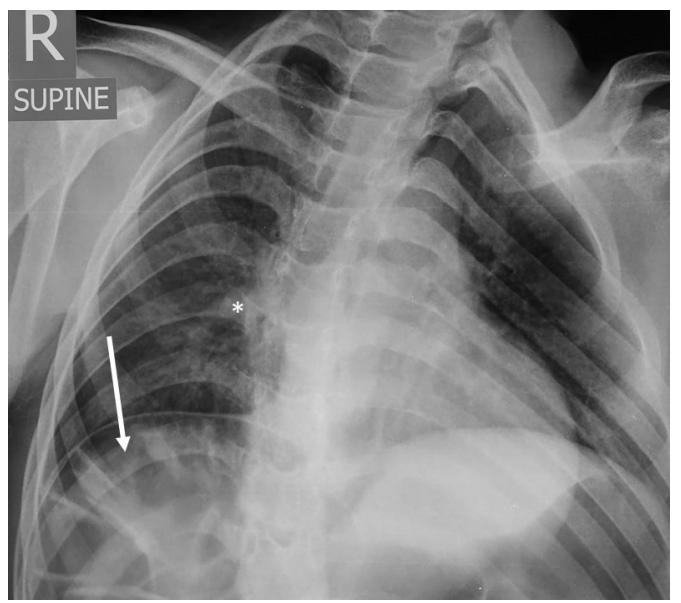

Figure 1 X-ray chest showing air bronchogram (asterisk) and classic Chilaiditi sign (white arrow).

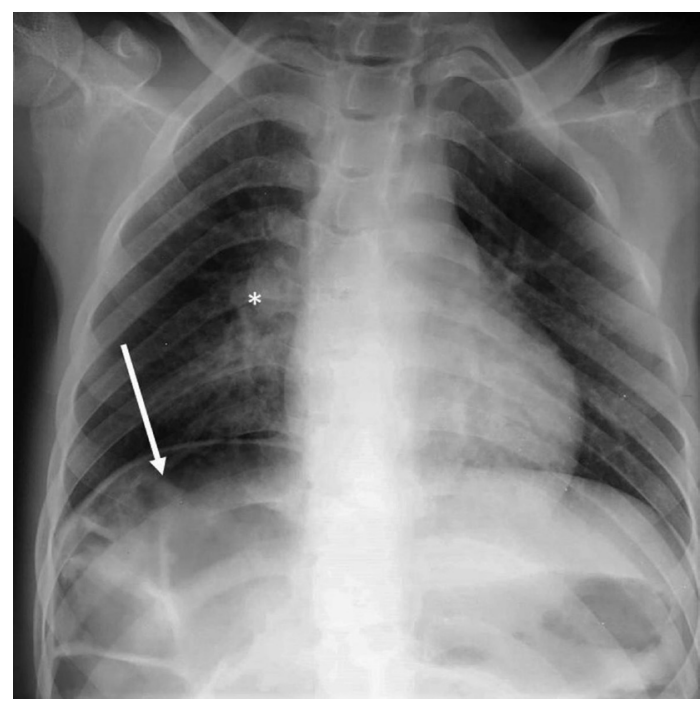

Figure 2 X-ray chest during follow-up with previous findings of air bronchogram (asterisk) and Chilaiditi sign (white arrow).

loops between the liver and diaphragm, which was previously undiagnosed.

The chest X-ray finding in this case is in line with what is called 'Chilaiditi sign'. Chilaiditi syndrome is the anterior disposition of the colon near the anterior hemidiaphragm, which is associated with pain and is an extremely rare condition. A diagnostic feature of Chilaiditi syndrome is the presence of Chilaiditi sign as seen in the case, which occurs in only $0.1 \%$ of all $\mathrm{X}$-rays taken. Pain is the main feature that differentiates Chilaiditi syndrome from Chilaiditi sign. In this study, because pain is present and there is Chilaiditi sign, we can successfully diagnose the case as having Chilaiditi syndrome.

The recurrent pneumonia in our case is due to his congenital abnormalities, which led to aspiration and due to the diaphragmatic irritation of the pleura. The development of pericarditis would have been caused due to pericardial injury because of the motion of the colon into the mediastinum. ${ }^{2}$ In later stages, the bowel loops under the diaphragm can severely compress the lungs and eventually the heart or surrounding organs and present with symptoms of heart disease. ${ }^{3}$ Chilaiditi syndrome is the cause and a great imitator of many diseases. Even though rare, the diagnosis can be made easily if aware of Chilaiditi syndrome.

The patient was started on ibuprofen for his pericarditis and a course of antibiotics for associated urinary tract infection along with baclofen. Currently, he is stable. A month later, chest X-ray was repeated and was unremarkable according to our 


\section{Learning points}

- Chilaiditi sign is a very rare finding on $\mathrm{X}$-ray and is often missed; though easy to diagnose, it has a very high morbidity.

- In cases presenting with chest pain along with abdominal pain, Chilaiditi syndrome should be in the differential diagnosis.

- Pericarditis should be a marker for underlying mediastinal and subdiaphragmatic conditions.

case (figure 2). Surgical management should be considered if this condition complicates keeping in mind the patient's long medical history.

Acknowledgements We would like to acknowledge Dr Fatima Khan (Shady Grove Hospital,Department of Internal Medicine, Maryland, USA) and Dr Imran Rashid (Department of Internal Medicine, RAK College of Medical Sciences, R.A.K, UAE) for their help and support.
Contributors The patient's history was taken in full and X-Ray findings were noted by MIA and BEE. BEE provided the files and images. MIA examined the X-Ray and thereby planned to write a case report as the finding was rare. MIA wrote part of the case history and discussion, SM and MIA edited the pictures. SM wrote the key points after discussing with MIA. BEE has also given an overview of the entire process and has helped in each instance.

Funding The authors have not declared a specific grant for this research from any funding agency in the public, commercial or not-for-profit sectors.

Competing interests None declared.

Patient consent Obtained.

Provenance and peer review Not commissioned; externally peer reviewed.

(c) BMJ Publishing Group Ltd (unless otherwise stated in the text of the article) 2018. All rights reserved. No commercial use is permitted unless otherwise expressly granted.

\section{REFERENCES}

1 Chen SY, Chen NF, Lu CS. Chilaiditi syndrome. QJM 2016:109:625-6.

2 Sorrentino D, Bazzocchi M, Badano L, et al. Heart-touching Chilaiditi's syndrome. World J Gastroenterol 2005;11:4607.

3 Okiro JO. Chilaiditi syndrome mimicking congestive heart failure. BMJ Case Rep 2017:2017:bcr-2017-220811.

Copyright 2018 BMJ Publishing Group. All rights reserved. For permission to reuse any of this content visit http://group.bmj.com/group/rights-licensing/permissions.

BMJ Case Report Fellows may re-use this article for personal use and teaching without any further permission.

Become a Fellow of BMJ Case Reports today and you can:

- Submit as many cases as you like

- Enjoy fast sympathetic peer review and rapid publication of accepted articles

- Access all the published articles

- Re-use any of the published material for personal use and teaching without further permission

For information on Institutional Fellowships contact consortiasales@bmjgroup.com

Visit casereports.bmj.com for more articles like this and to become a Fellow 